\title{
Neuroendocrine appendiceal tumor and endometriosis of the appendix: a case report
}

\author{
Rogério Serafim Parra ${ }^{1,2^{*}}$ (D) Marley Ribeiro Feitosa ${ }^{1,2}$, Giovana Bachega Badiale Biagi ${ }^{3}$, Daniel Ferracioli Brandão ${ }^{3}$, \\ Margarida Maria Fernandes da Silva Moraes ${ }^{3}$, Liliane Silvestre ${ }^{4}$, José Vitor Cabral Zanardi ${ }^{5}$, \\ Nelson Hitamo Sato Junior ${ }^{5}$, Omar Féres ${ }^{1,2}$ and José Joaquim Ribeiro da Rocha $a^{1,2}$
}

\begin{abstract}
Introduction: Endometriosis of the appendix is very uncommon, accounting for only about $1 \%$ of all cases of endometriosis. However, endometriosis is found in the appendix in approximately $8-13 \%$ of patients with deep infiltrating endometriosis and is particularly common in patients with severe forms of deep infiltrating endometriosis. Neuroendocrine tumors are the most common neoplasms of the appendix and may be misdiagnosed when there are multiple endometriosis lesions in the pelvis.

Case presentation: We describe a case of a Caucasian patient with deep infiltrating endometriosis with rectal involvement, retrocervical lesions, and a right ovarian endometrioma with no suspected lesions in the appendix. She underwent laparoscopy and, after a systematic intraoperative evaluation, suspected involvement of the appendix was observed. The patient underwent ovarian cystectomy, excision of the pelvic endometriosis lesions, appendectomy, and anterior stapler discoid resection. Histopathological analysis of the appendix revealed endometriosis and a well-differentiated neuroendocrine carcinoma at the appendix tip.
\end{abstract}

Discussion: Our patient's case emphasizes the need to approach these lesions carefully and strengthens the indication for appendectomy when the appendix is affected in the setting of endometriosis. Despite the more likely diagnosis of appendiceal endometriosis, neuroendocrine tumors cannot be ruled out by imaging examinations, and both conditions can occur in the same patient.

Keywords: Appendiceal neoplasm, Appendix, Neuroendocrine tumor, Endometriosis, Deep infiltrating endometriosis

\section{Introduction}

Endometriosis is a common benign disease that affects approximately $10 \%$ of women of reproductive age and is associated with chronic pelvic pain, dyspareunia, and infertility [1]. Deep infiltrating endometriosis (DIE) is the

\footnotetext{
*Correspondence: rsparra@hcrp.usp.br

'Proctogastroclinic, Eliseu Guilherme St, 09, Ribeirão Preto, SP, Brazil

${ }^{2}$ Department of Surgery and Anatomy, School of Medicine of Ribeirão Preto, University of São Paulo, Sao Paulo, Brazil

Full list of author information is available at the end of the article
}

most severe type and often affects the bowel (up to 25\% of cases), particularly the rectosigmoid colon, and occasionally may be found in the ileum, cecum, and appendix $[2,3]$. Surgery is indicated in patients with pelvic pain who do not respond to medical therapy and/or in patients with ileal involvement, owing to the risk of intestinal obstruction, and in those with appendiceal involvement, owing to the higher risk of neoplasia in these cases $[2,4]$. Previous studies have suggested that appendiceal endometriosis is not a rare entity and occurs in 
up to $2.8 \%$ of patients with endometriosis [5] and up to $13.2 \%$ of patients with DIE [4]. The percentage is higher in patients with more severe disease or in those with lesions at multiple sites [4]. Therefore, systematic intraoperative evaluations of the appendix should be performed in patients with endometriosis, and in the presence of nodules, appendectomy must be considered [6, 7]. Neuroendocrine tumors are the most common neoplasms of the appendix and are detected in $0.16-2.3 \%$ of all appendectomies [8].

\section{Case presentation}

A 45-year-old Caucasian woman was referred to our institution for deep dyspareunia, chronic pelvic pain, and dysmenorrhea. Her medical history revealed antidepressant treatment with no other family or personal history. She had previously undergone two failed in vitro fertilization treatments for infertility and had a history of previous treatments for endometriosis, including one laparoscopy. Her previous laparoscopy was performed in another institution (excision of superficial peritoneal nodules and uterosacral ligament). No bowel involvement was observed at first operation. Clinical examination showed absence of abdominal masses, mild pain on palpation of the lower abdomen, moderate pain on vaginal touch on uterine mobilization, and discomfort on rectal touch when the rectovaginal septum was palpated. Transvaginal ultrasound (TVU) (Fig. 1) with bowel preparation showed signs of deep endometriosis with rectal involvement $(9 \mathrm{~cm}$ of anal verge, $40 \%$ of the circumference of the rectum, $2.0 \times 0.7 \times 1.3 \mathrm{~cm}$ ), retrocervical lesions, and a $4.5-\mathrm{cm}$ right ovarian endometrioma with no suspected lesions in the appendix. The patient did not undergo any other radiological imaging. She underwent laparoscopic surgery. A systematic intraoperative evaluation during laparoscopy revealed suspected involvement of the appendix with deep endometriosis. The patient then underwent ovarian cystectomy, excision of the pelvic endometriosis lesions, appendectomy, and anterior stapler discoid resection (Fig. 2). She was discharged in 1 day and had no postoperative complications. Histopathological analysis of the rectum and ovarian cystectomy confirmed extensive

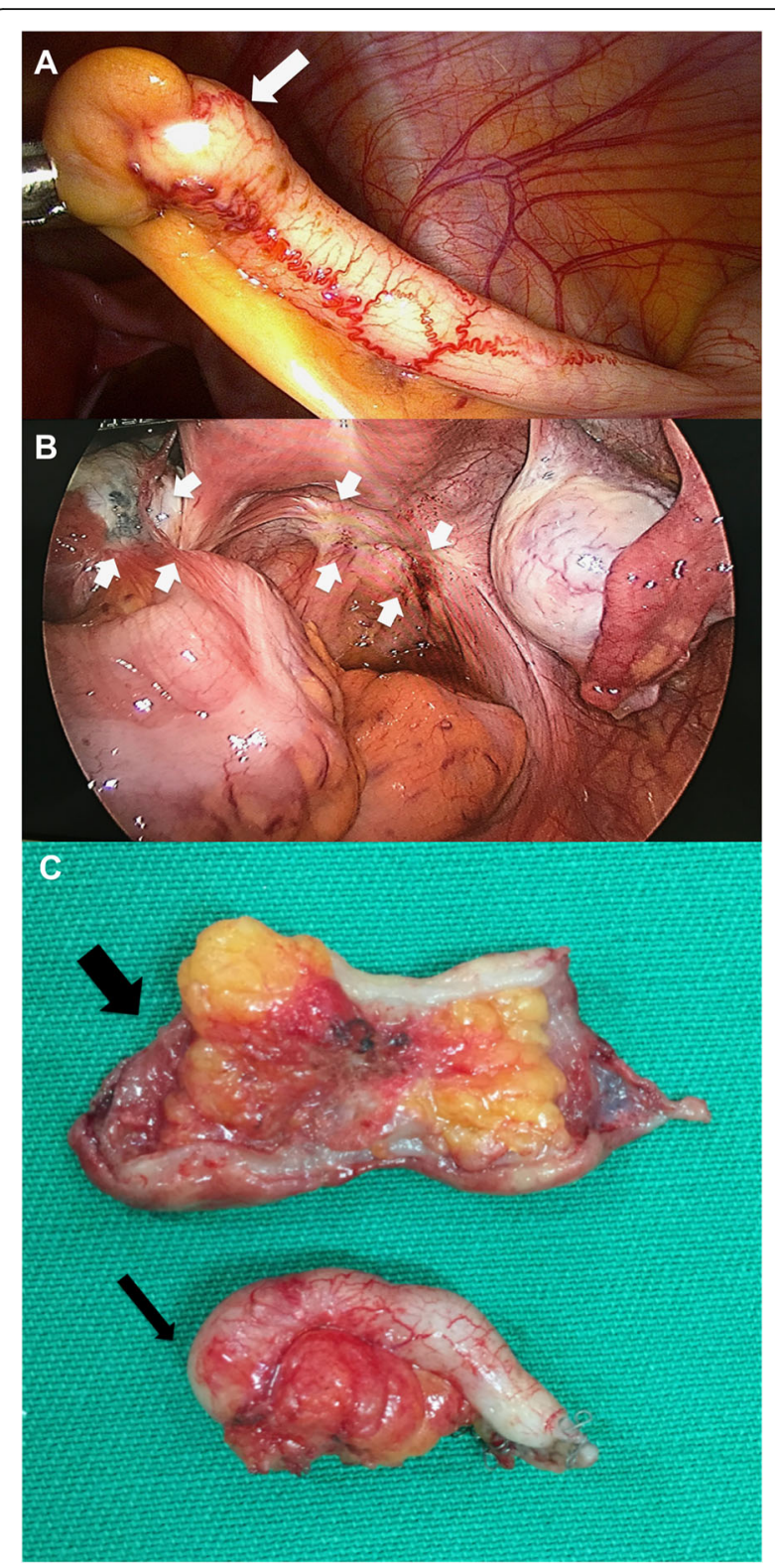

Fig. 2 a Appendix with a nodular lesion at the tip (arrow). b Intraoperative evaluation of pelvic cavity showing (or revealing) endometriosis (arrows); c Surgical specimen (appendectomy - thin arrow; anterior stapler discoid resection - large arrow)

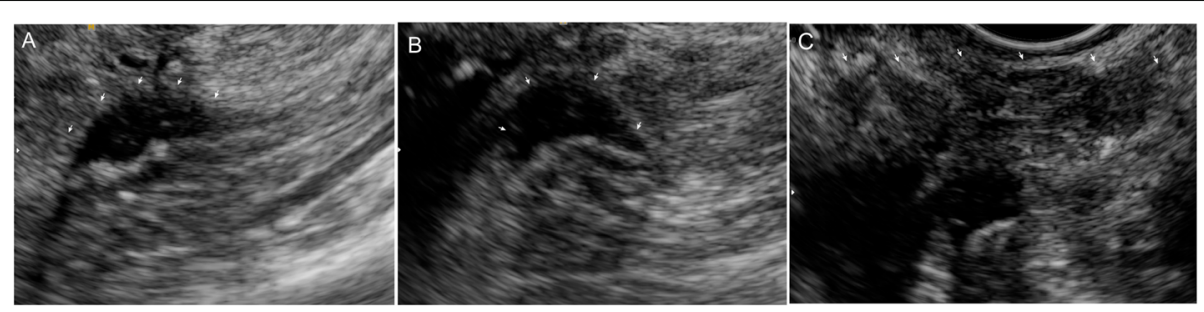

Fig. 1 a Transvaginal ultrasound with bowel preparation: deep infiltrative endometriosis with rectal involvement, $9 \mathrm{~cm}$ of anal verge, $40 \%$ of circumference of rectum, $2.0 \times 0.7 \times 1.3 \mathrm{~cm}$. b Retrocervical lesions. c $4.5-\mathrm{cm}$ right ovarian endometrioma 


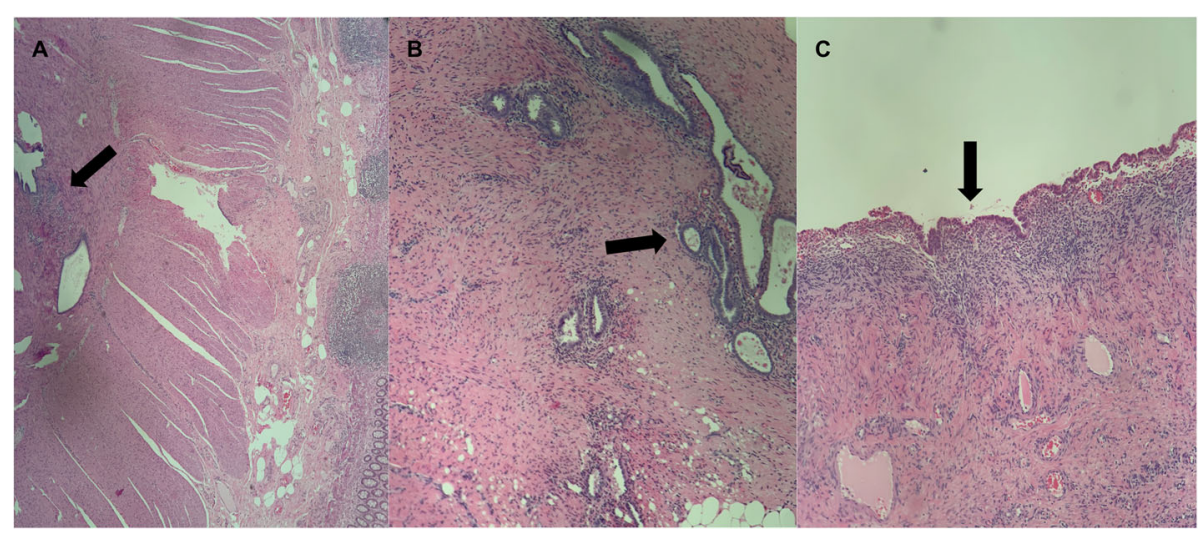

Fig. $3 \mathbf{a}$ and $\mathbf{b}$ Histopathological analysis of the rectum (arrow). c Histopathological analysis of the ovarian cystectomy (arrow). Both analyses confirmed extensive endometriosis involvement Hematoxylin and eosin (H\&E) stain, original magnification $100 \times$ and $400 \times$ )

endometriosis involvement (Fig. 3), and the analysis of the appendix revealed endometriosis and a welldifferentiated neuroendocrine carcinoma at the appendix tip that was $1.3 \mathrm{~cm}$ in size and infiltrated the adipose appendicular tissue with angiolymphatic invasion and free surgical margins (Fig. 4). Immunohistochemical analysis revealed positivity for Ki67/MIB-1 in 1.5\% of the cells (Fig. 5). Right colectomy was indicated due to infiltration of the adipose tissue and due to angiolymphatic invasion, but the patient refused. She is currently being followed up, and, after 2 years, she has no signs of recurrence.

\section{Discussion}

This study reinforces the importance of a complete evaluation of the peritoneal cavity, including the appendix, during laparoscopy for patients with DIE. In the presence of suspected lesions, appendectomy should always be performed. Previous studies demonstrated that endometriosis might be a cancer precursor; the mutations that are present in endometriosis-associated cancers can be found in adjacent endometriosis lesions [9].
It is important to state that the severity of patient symptomatology and disease state are not correlated, ranging from asymptomatic patients to patients with a myriad of complaints, including but not limited to dysmenorrhea, chronic pelvic pain, dyspareunia, infertility, fatigue, and cyclic urinary and intestinal symptoms according to the location of the disease. Lesions can be single or multifocal, including involvement of the appendix when endometriosis with intestinal involvement is present $[10,11]$.

Endometriosis of the appendix is very uncommon, accounting for only about $1 \%$ of all cases of endometriosis. However, in patients with endometriosis of the appendix, other sites are commonly affected by the disease, mainly the bladder and rectosigmoid and retrocervical regions. When these characteristics are present or if patients have more than three sites affected by endometriosis, the surgeon should evaluate the appendix carefully [12].

Our imaging protocol includes evaluation with TVS with a high-resolution linear transducer and bowel preparation in all patients to map the endometriosis lesions of the right iliac fossa and to detect lesions of the ileum,

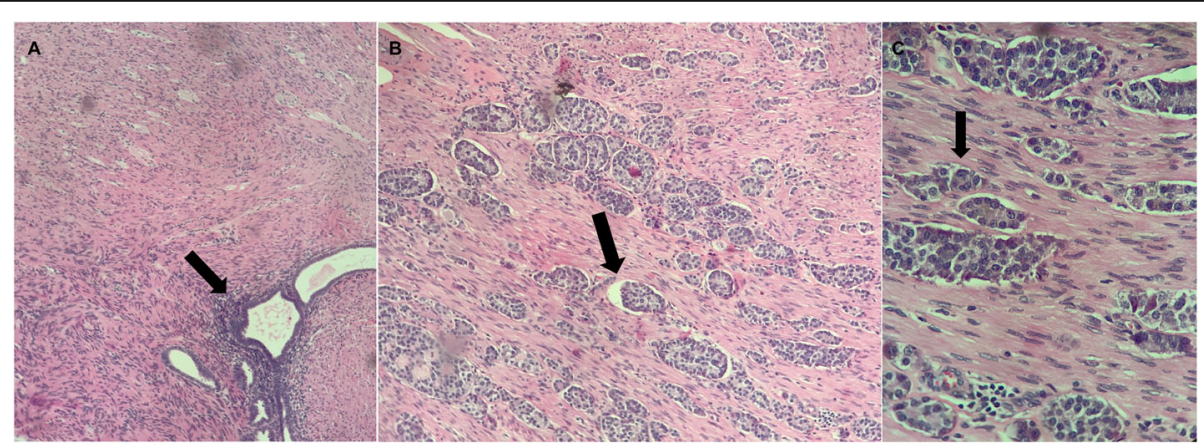

Fig. 4 Histopathological analysis of the appendix. The analysis confirmed endometriosis (arrow) (a) and a well-differentiated neuroendocrine carcinoma infiltrating the adipose appendicular tissue, with angiolymphatic invasion and free surgical margins (arrow) (b and $\mathbf{c}$ ) (Hematoxylin and eosin (H\&E) stain, original magnification $100 \times$ and $400 \times$ ) 


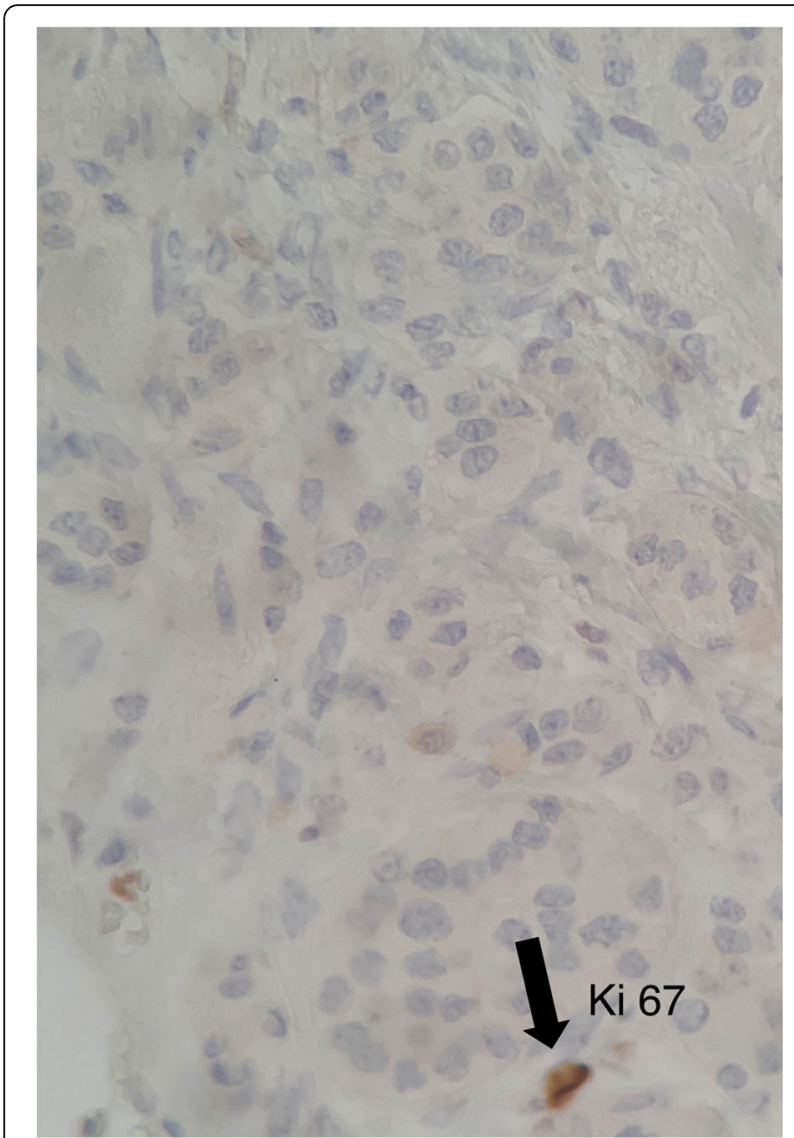

Fig. 5 Immunohistochemical analysis. Positivity for Ki67/MIB-1 in $1.5 \%$ of cells (original magnification $400 \times$ )

cecum, and appendix, as observed by other authors [6, 13]. Previous studies showed that ultrasonography has diagnostic accuracy not inferior to magnetic resonance imaging (MRI). The diagnostic performance of TVU and MRI are similar for detecting DIE involving the rectosigmoid colon, uterosacral ligaments, and rectovaginal septum. Therefore, it must be considered the primary approach for DIE diagnosis [14-16].

Appendectomy is mandatory when, during laparoscopic surgery for DIE, any abnormalities, such as the presence of nodules, thickening, swelling, or adhesions suggestive of disease in the appendix, are found, because the diagnosis of neuroendocrine tumor cannot be ruled out [6]. In addition [17, 18], a retrospective cohort study of patients with DIE with intestinal involvement was performed at our referral center from September 2014 to May $2019(\mathrm{~N}=124)$ [19] and showed appendiceal endometriosis in 12 patients (9.7\%). Among all these patients, the presence of appendiceal neoplasia was detected in one patient, leading to a frequency of appendiceal neoplasia of 1 in $12(8.3 \%)$ among all our appendectomies and 1 in $124(0.8 \%)$ of all surgeries for DIE with intestinal resection. The incidence of appendectomies in our series is comparable with that in other series [4, 12], which reinforces the importance of a complete evaluation of the peritoneal cavity during laparoscopy in patients with DIE. In addition, it is essential to map the endometriosis lesions during the preoperative evaluation to facilitate surgical planning and ensure a complete evaluation of the intestine during laparoscopy.

Neuroendocrine tumors are detected in $0.16-2.3 \%$ of all appendectomies [8]. Generally, the prognosis is good, and the 5-year survival rate is higher than 95\% [20]. Metastasis to regional lymph nodes and distant metastasis occur in approximately $4 \%$ and $1 \%$ of patients, respectively, usually when the primary tumor is larger than $2 \mathrm{~cm}$. Appendectomy has been recommended as the treatment for appendiceal neuroendocrine tumors smaller than $1 \mathrm{~cm}$ in the guidelines set by the North American Neuroendocrine Tumor Society (NANETS). NANETS recommends right hemicolectomy in the following situations: tumors originating at the base of the appendix, tumors exceeding $2 \mathrm{~cm}$ in size, evidence of lymphovascular or mesoappendiceal invasion, lymph node metastasis, presence of regional lymph node metastasis, high mitotic count, peritoneal studding or angioinvasion, and intermediate or high-grade tumors [21]. If the proximal resection margin alone is involved, conservative local reexcision may be considered $[6,20]$.

In our patient's case, we recommended a right colectomy to the patient, according to the recommendation described above. However, the patient refused to undergo another surgery. The colectomy was indicated by the histopathological results of angiolymphatic invasion. However, after follow-up of 24 months, the patient was free of recurrence. Recurrence has been tracked by imaging methods performed every 6 months.

\section{Conclusion}

Our patient's case emphasizes the need to approach these lesions carefully and strengthens the indication for appendectomy when the appendix is affected in the setting of endometriosis.

\section{Abbreviations}

DIE: Deep infiltrating endometriosis; MRI: Magnetic resonance imaging; NANE TS: North American Neuroendocrine Tumor Society

\section{Acknowledgements}

The transvaginal ultrasound with bowel preparation was a courtesy of Dr. Liliane Silvestre, Nucleus Diagnosis and Medicine. The authors thank Dr. Daniel Ferracioli Brandão of M\&M Laboratory of Pathology and Cytology for helping with the image preparation. The authors thank Dr. Nelson Sato Jr. for his help with laparoscopic surgery and patient follow-up.

\section{Authors' contributions}

RSP was responsible for study design, data collection, manuscript writing, and figure preparation. MRF was responsible for figure preparation and critical revision. GBBB was responsible for figure preparation and literature review. MMFdSM was responsible for figure preparation and literature review. JJRdR was responsible for critical revision. OF was responsible for 
critical revision. DFB, LS, JVCZ, and NHS were responsible for images preparation and literature review. All authors contributed to the analysis and interpretation of data and revision of the manuscript for important intellectual content, and all authors granted final approval of the version to be published and agreed to be accountable for all aspects of the work in ensuring that questions related to the accuracy or integrity of any part of the work are appropriately investigated and resolved. All authors read and approved the final manuscript.

\section{Funding}

None.

\section{Availability of data and materials}

The datasets supporting this article are included within the article.

\section{Ethics approval and consent to participate}

We declare that the study met all the research ethics criteria and was fully approved by our institutional review board (no. 04/2019; October 10, 2019). All procedures were in accordance with the ethical standards of the responsible institutional and national committee on human experimentation and with the 1964 Helsinki declaration and its later amendments or comparable ethical standards.

\section{Consent for publication}

Written informed consent was obtained from the patient for publication of this case report and any accompanying images. A copy of the written consent is available for review by the Editor-in-Chief of this journal.

\section{Competing interests}

All authors declare that they have no competing interests.

\section{Author details}

'Proctogastroclinic, Eliseu Guilherme St, 09, Ribeirão Preto, SP, Brazil.

${ }^{2}$ Department of Surgery and Anatomy, School of Medicine of Ribeirão Preto, University of São Paulo, Sao Paulo, Brazil. ${ }^{3} \mathrm{M} \& \mathrm{M}$ Laboratory of Pathology and Cytology, Ribeirão Preto, SP, Brazil. ${ }^{4}$ Nucleus - Diagnostic Medicine, SP, Ribeirão Preto, Brazil. ${ }^{5}$ Fecunditá Clinic, Ribeirão Preto, SP, Brazil.

Received: 27 March 2020 Accepted: 7 August 2020

Published online: 14 September 2020

\section{References}

1. Shafrir AL, Farland LV, Shah DK, et al. Risk for and consequences of endometriosis: a critical epidemiologic review. Best Pract Res Clin Obstet Gynaecol. 2018:51:1-15.

2. Abrao MS, Petraglia F, Falcone T, Keckstein J, Osuga Y, Chapron C. Deep endometriosis infiltrating the recto-sigmoid: critical factors to consider before management. Hum Reprod Update. 2015;21(3):329-39.

3. Borghese B, Santulli P, Marcellin L, Chapron C. Definition, description, clinicopathological features, pathogenesis and natural history of endometriosis: CNGOF-HAS Endometriosis Guidelines [in French]. Gynecol Obstet Fertil Senol. 2018:46(3):156-67.

4. Moulder JK, Siedhoff MT, Melvin KL, Jarvis EG, Hobbs KA, Garrett J. Risk of appendiceal endometriosis among women with deep-infiltrating endometriosis. Int J Gynaecol Obstet. 2017;139(2):149-54.

5. Gustofson RL, Kim N, Liu S, Stratton P. Endometriosis and the appendix: a case series and comprehensive review of the literature. Fertil Steril. 2006; 86(2):298-303.

6. Padovesi Mota IL, Klajner S, da Costa Gonçalves MO, Passman LJ, Podgaec S Appendiceal nodules in the setting of endometriosis can be carcinoid tumors. JSLS. 2015;19(3):e2015.00028.

7. Abrao MS, Myung LHJ, Averbach M, Kho RM. Neuroendocrine tumor or endometriosis of the appendix: which is which? J Minim Invasive Gynecol. 2020;27(1):15-6.

8. Moris D, Tsilimigras DI, Vagios S, et al. Neuroendocrine neoplasms of the appendix: a review of the literature. Anticancer Res. 2018;38(2):601-11.

9. Dawson A, Fernandez ML, Anglesio M, Yong PJ, Carey MS. Endometriosis and endometriosis-associated cancers: new insights into the molecular mechanisms of ovarian cancer development. Ecancermedicalscience. 2018; 12:803.
10. Vercellini P, Fedele L, Aimi G, Pietropaolo G, Consonni D, Crosignani PG. Association between endometriosis stage, lesion type, patient characteristics and severity of pelvic pain symptoms: a multivariate analysis of over 1000 patients. Hum Reprod. 2007;22(1):266-71.

11. Parasar P, Ozcan P, Terry KL. Endometriosis: epidemiology, diagnosis and clinical management. Curr Obstet Gynecol Rep. 2017;6(1):34-41.

12. Abrão MS, Dias JA, Rodini GP, Podgaec S, Bassi MA, Averbach M. Endometriosis at several sites, cyclic bowel symptoms, and the likelihood of the appendix being affected. Fertil Steril. 2010;94(3):1099-101.

13. Goncalves MO, Podgaec S, Dias JA Jr, Gonzalez M, Abrao MS. Transvaginal ultrasonography with bowel preparation is able to predict the number of lesions and rectosigmoid layers affected in cases of deep endometriosis, defining surgical strategy. Hum Reprod. 2010;25(3):665-71.

14. Noventa M, Scioscia M, Schincariol M, et al. Imaging modalities for diagnosis of deep pelvic endometriosis: comparison between trans-vaginal sonography, rectal endoscopy sonography and magnetic resonance imaging: a head-to-head meta-analysis. Diagnostics (Basel). 2019;9(4):225.

15. Guerriero S, Ajossa S, Minguez JA, et al. Accuracy of transvaginal ultrasound for diagnosis of deep endometriosis in uterosacral ligaments, rectovaginal septum, vagina and bladder: systematic review and meta-analysis. Ultrasound Obstet Gynecol. 2015;46(5):534-45.

16. Guerriero S, Saba L, Pascual MA, et al. Transvaginal ultrasound vs magnetic resonance imaging for diagnosing deep infiltrating endometriosis: systematic review and meta-analysis. Ultrasound Obstet Gynecol. 2018;51(5): 586-95

17. Laskou S, Papavramidis TS, Cheva A, et al. Acute appendicitis caused by endometriosis: a case report. J Med Case Rep. 2011;5:144.

18. Emre A, Akbulut S, Yilmaz M, Bozdag Z. An unusual cause of acute appendicitis: appendiceal endometriosis. Int J Surg Case Rep. 2013;4(1):54-7.

19. Parra R. Surgical laparoscopic treatment of deep endometriosis with bowel involvement. a retrospective cohort study [abstract]. UEG J. 2019;7:865. In: Zanardi J, Valério F, Feitosa M, Féres O, Rocha J, eds.

20. Carr NJ, Sobin LH. Neuroendocrine tumors of the appendix. Semin Diagn Pathol. 2004;21(2):108-19.

21. Elkbuli A, Sanchez C, McKenney M, Boneva D. Incidental neuro-endocrine tumor of the appendix: Case report and literature review. Ann Med Surg (Lond). 2019;43:44-7.

\section{Publisher's Note}

Springer Nature remains neutral with regard to jurisdictional claims in published maps and institutional affiliations.

Ready to submit your research? Choose BMC and benefit from:

- fast, convenient online submission

- thorough peer review by experienced researchers in your field

- rapid publication on acceptance

- support for research data, including large and complex data types

- gold Open Access which fosters wider collaboration and increased citations

- maximum visibility for your research: over $100 \mathrm{M}$ website views per year

At $\mathrm{BMC}$, research is always in progress.

Learn more biomedcentral.com/submissions 